\title{
DESIGN OF THE RESEARCH BASED TRAINING IN TECHNOLOGIES AND ENTREPRENEURSHIP IN THE SECONDARY EDUCATION
}

\author{
Maia Angelova Stoeva, ${ }^{1}$ Sashko Plachkov, ${ }^{2}$ Diana Mitova, ${ }^{3}$ Lyubima Zoneva ${ }^{4}$
}

\begin{abstract}
The article presents the nature of the research approach and its application in the framework of the studied disciplines of the cycle of technological training. Presented are the results of monitoring study of the skills of 11-14 year old students for research. The design of research-oriented training in technology and entrepreneurship predisposes the increase of the interest in the learning process and the learning motivation in parallel with the implementation of basic educational goals.

The suggested tools aim to diagnose the skills of the students in the research training. Described are the basic levels of administration of the research approach in the training and its influence on building skills on a high level (at meta-level) in the students. The idea is similar to Bloom's taxonomy according to which levels that follow the logical transition from easy to difficult act in the cognitive sphere.

Knowledge and basic intellectual skills formed during are explored, with an emphasis on problem-solving cognitive and practical tasks. The creative technical abilities of the students are being studied through case studies and situations, and an algorithm for key research projects has been developed.

The focus is on the interdisciplinary research training project which requires a broad general culture and knowledge from various scientific fields. A critical analysis of the results and conclusions about changes in teaching practice takes a special place in the article.
\end{abstract}

UDC Classification: 37.01/.09, 37.02; DOI: http://dx.doi.org/10.12955/cbup.v5.981

Key words: Educational design, competent approach, research-based learning, research project, technological education

\section{Introduction}

The quality education is based on the use of progressive strategies for teaching and learning, among which an important place is assigned to the research training. Modern educational transformations imply a subject-subjective pedagogical interaction and transition from the reproductive to the creative type teaching and learning. In the activity-oriented model, education is targeted at students, stimulating their productive thinking and creativity. The current educational trends help to move the focus from receiving just knowledge to independent learning through personal experience and impressions, through solving real life problems and active research.

One of the directions for upgrading the technological training and entrepreneurship in the Bulgarian educational system is to strengthen the research activity of students through direct participation in research.

\section{Scientific research as a method of thinking and solving problems in the school environment}

Each scientific research has specific characteristics which distinguish it from other research methods. Depending on the scientific method, research is described as theoretical, empirical, fundamental, and applied. It can be performed in nature or in a laboratory environment, or real objects or test models or samples. (Dimitrov, 2013)

The ability of students to think is developed using modern methods of teaching and learning as problem-based learning or training based on research approach. In the process of scientific inquiry, learners discover and solve research tasks and problems of different nature. Their ability to comprehend the learning material and its application to achieve certain scientific goals is evaluated through solving research tasks. The tasks are directly related to the skills of students to formulate objective, tasks, object, subject, and hypothesis, to select and present the methodology of his research (phases and methods of study) to seek, analyze, summarize and present scientific information, conduct scientific monitoring to model (in the course of experimental work), and to present results.

Solving problems in the process of teaching - research goes through different stages: exploration sources of information, analysis, synthesis, comparison, systematization, classification, typing, monitoring, research, experiment, and others. The process of experimentation is associated with

\footnotetext{
${ }^{1}$ Faculty of Engineering, South-West University "Neofit Rilski" Blagoevgrad, Bulgaria, maia_angelova67@ @wu.bg

${ }^{2}$ Faculty of Engineering, South-West University "Neofit Rilski" Blagoevgrad, Bulgaria, maia_angelova67@swu.bg

${ }^{3}$ Faculty of Engineering, South-West University "Neofit Rilski" Blagoevgrad, Bulgaria, didimitova2006@ swu.bg

${ }^{4}$ Faculty of Engineering, South-West University "Neofit Rilski" Blagoevgrad, Bulgaria, zoneva@ swu.bg
} 
establishing causal connections and relationships, taking into account the variables and interactions in solving practical problems.

The ability to solve problems is one of the key competencies of the $21^{\text {st }}$ century, and its formation in the school environment is of critical importance.

Competence to solve problems is related to the mobilization of cognitive and practical skills of the student, his creative abilities, values, and motivations. Solving problems is associated with the capacity of students to use the knowledge acquired in school to cope with the challenges of real life. At the core of solving the problem is the analysis of the reasons that cause it. It requires the ability to understand its nature and necessity problem to be recognized, considered and properly defined. The process includes the definition of the specific problem, the planning to find solution and choice of action strategies, performance, control and evaluation of the outcome. The problem represents a problematic situation on a smaller scale or a part of it. The formulation of the problematic situation requires creative and analytical thinking. The process of solving the problem represents specific research activity which begins with the study of the unfamiliar situation to determine the obstacles and the possibilities for the further steps. (Petrova, 2012)

The problematic situation is a state of intellectual disability, of which the student is looking for answers. It occurs when the knowledge and the experience, gained by the instant, are not sufficient for the solution of the problem. Learning how to solve problems is based on the creative abilities and comprehensive independence of the students. The Learning problem is a practical or a theoretical difficulty to which the solution is a result of the research activity of the student. It suggests a combination of knowledge from various scientific areas, giving the opportunity to the learners to independently apply the already acquired knowledge in a new situation.

We can mention the following requirements in formulating educational problem: it should be related to the already studied educational discipline and should have a logical connection with the achieved skills and knowledge; the formulation of the problem should contain both known and new terms; should contain cognitive difficulties; should be optimally difficult; should reflect contradictory information; the content of the problem should point to finding solutions; and finally it should cause cognitive interest for students.

Problematic situations require from the student's complex mental activities, oriented to alternately rising and checking of different hypothesis, self-absorption of new knowledge and experience, and reaching logically reasoned findings and conclusions. Independent work of students to solve problems is often closer to the actual research. Each problematic task provokes deductive, inductive and combinatorial thinking, thinking through analogies, and creative thinking of students.

This study focuses on the following cognitive competencies and forms of mental activity:

- Formation of terms that place the base of the abstract knowledge;

- Planning a series of activities to achieve a particular result;

- Decision-making through choice between alternative strategies;

- Problem-solving through a series of actions (steps);

- Opportunity for reflection by exposing the evidence to support these conclusions and reaching conclusions;

- Manifestation of creative imagination and create new images and objects through participation in research activities.

Research skills suggest the targeted use of scientific and technical concepts and basic scientific theories that are characteristic of the research. In particular, these are the skills the student use to identify logically justified questions: to make observations and to ask questions; to collect, analyze and present information; to compare decisions, experiences or hypotheses; to forecast and to reach conclusions with different levels of complexity; and to make objective conclusions and to assess the strengths and weaknesses of the conducted research. Research skills stimulate the scientific and technical thinking, supporting the objective interpretation of the information obtained and respectively the preparation of conclusions and predictions about future initiatives and career development in science and modern technologies.

Great attention is paid to the interrelation between these competencies here with three key competencies set out in the European Reference Framework - the digital competence, technological 
competence and competence called "initiative and entrepreneurship" (Plachkov, 2013). These competencies are the foundation of building a competency profile of both teachers and students on the subject "Technology and Entrepreneurship," which in turn determines the quality and direction of formation and expression of their research skills.

\section{The specifics of learning and research activities of students in the course "Technology and Entrepreneurship"}

The specific objectives of training in general subjects "Technology and Entrepreneurship" in Bulgarian schools have been limited to the establishment of basic technological competence of students, launching of formation of key competence initiative and entrepreneurship, formation of attitude towards a healthy and safe lifestyle and work to create conditions for conscious choice of education and profession.

Technological competence is associated with the use of the equipment for manual and machine processing of materials, self-development projects through the application of available software and digital communication and control. To manifest initiative and entrepreneurship, it is planned to enter in the real economic environment, exploring the best entrepreneurial practices and examples of entrepreneurial initiative. Considerable emphasis is placed on the key competencies and learning skills, critical thinking, problem solving, decision making, initiative, creativity, responsibility, and teamwork. (Ministry of Education and Science of the Republic of Bulgaria, 2015).

Educational and research activities of the students in the process of technological learning is a form of active learning and use of theoretical and empirical methods of scientific research. This activity is organized by the teacher who plans, creates and directs the process of learning. Content determination of training suggests opportunities to address diverse learning tasks, having the features of the research process. Educational activities have a research nature related to solving various design, technology, and organizational tasks. Structures will be analyzed, tools and technological operations - selected, the value and cost of products will be calculated, technical and technological objects will be evaluated as well as social phenomena and processes, and choice, based on certain criteria will receive argumentation. Organization of training in technology and entrepreneurship involves conducting integrated lessons, laboratory work and the development of projects that are leading teamwork and learning through search.

The laboratory training as one of the organizational forms of technological education provides the following opportunities for educational research:

- Research of physico-mechanical and technological characteristics of the materials;

- Measuring physical quantities with digital equipment and basic electrical parameters (power, voltage, resistance, size of the electric current, etc.).

- Identifying any changes in parts and products subjected to mechanical and thermal effects;

- Establishing a compliance between working process and working environment for a given profession;

- Establishing major motivational features and determining interest in a profession.

The educational content provides an opportunity for individual and team development of ideas and implementation of projects on topic, where the techniques of manual and machine processing of materials and products are used, and affordable digital software and digital means of communication and control are applied. Activities, related to entering the real economic environment, exploring the best entrepreneurial practices and platform for the entrepreneurial initiative, are stimulated. The ideas for project work are oriented to: constructive modifications to objects, design of structural assignment, development of options for family budget, research and development of ideas for entrepreneurial activity, realization of models of automatic electromagnetic and photo relay, performing market research and production of promotional materials for the company performance, the development of virtual design of a small firm, computer-aided design, engineering products from environmentally friendly materials, research and evaluation of the organizational structure of the educational company and others.

The educational research project in the content framework of technological training represents a specific learning task, related to the implementation of planned activities and aims to achieve concrete pragmatically oriented results for a set time. The project has specific objectives oriented toward 
solving specific technical/technological problems. The specific objective of creative (research) project is based on research with a focus on a specific topic of the educational content of technological training. Students are required to have skills for planning, organization and time management during the implementation of the planned educational tasks. Criteria for evaluation of the project can be: the selection and formulation of the theme of the project; concretization of tasks; selection of appropriate methods for accomplishing the design research task; the presentation of the collected information; the selection of participants, resources, sites for the project, meeting deadlines, etc. (Mitova, 2011)

\section{Methodology and research approach}

The used research methodology is based on the methods of qualitative research - meaningful analysis of school records in technological training and testing (with problematic issues and practical tasks). The proposed tools aim to diagnose the interests of students to research training in the subjects of the cycle of technological training. With a view to implementing the research methodology, the following are identified:

- A complex of tasks and the respective criteria for analysis and evaluation of the level of preparation of children for research training in selected topics of the discipline "Technologies and Entrepreneurship"

- Criteria for the analysis of responses to tasks

- Measuring instruments - tests with questions and tasks tailored to specific technological training

Assessing the preparation of children for research training and skills for research is carried out through tasks for the detection and selection of certain information, questions and tasks with optional answer, questions with free and independently constructed response, and creative technical tasks in accordance with the set criteria.

The criteria for the analysis of results are reduced to: the mean scores of students; distribution of results in levels of achievement and performance, according to the measured cognitive processes and content areas.

We used the following criteria to evaluate the student responses (they match respectively low, medium and high level): completely true are the answers where the students give a correct answer or proper explanation (algorithm steps to solve the problem, creative interpretations); partially true - the answers are incomplete (partially true) without the necessary explanations; and wrong answers. In structuring the diagnostic technology assessment for the preparation of students for research training, the focus on the following components:

- Study of basic knowledge and intellectual skills formed in the process of learning, focusing on problem solving, cognitive and practical tasks from the content framework of technological training;

- Exploring the creative technical abilities of students through case studies and situations and developing conceptual algorithm designs with themes from the content of the subject "Technology and Entrepreneurship."

For a starting point in designing the diagnostic techniques are used the components of knowledge and skills of Bloom's taxonomy.

\section{Assessments of the study}

The survey results are quantitatively processed and are correlated to levels of research training. Included are tasks for the detection and selection of certain information, questions and tasks with multiple choice answers, questions with free and independently structured answer, and creative technical tasks. The solution of the tasks for the assessment of the research abilities is consistent with the cognitive levels of Bloom: knowledge, comprehension, application, analysis, synthesis, and evaluation.

The relevance of the results obtained for the 6th and 8th grades are clearly seen from the graph of Fig. 1. The analysis of quantitative data strongly suggests that in answering questions and solving problems, the students from 6th grade there is a dominating performance average in ascending plan and high level of bearish run. There is an uneven distribution of the results at a low level, but the 
trend, clearly shown in the chart with the line going upward, allows us to relate these results to the reproductive-adaptive level of expression of research skills.

It was found that tasks requiring expression skills of the highest cognitive level - evaluation, cause considerable difficulties in students from 8th grade. In tasks that require thinking through comparison of causalities and relations, abstraction, generalization of a match, and critical thinking related to the discretion of a situation, the results are the lowest regarding the levels of Bloom's taxonomy.

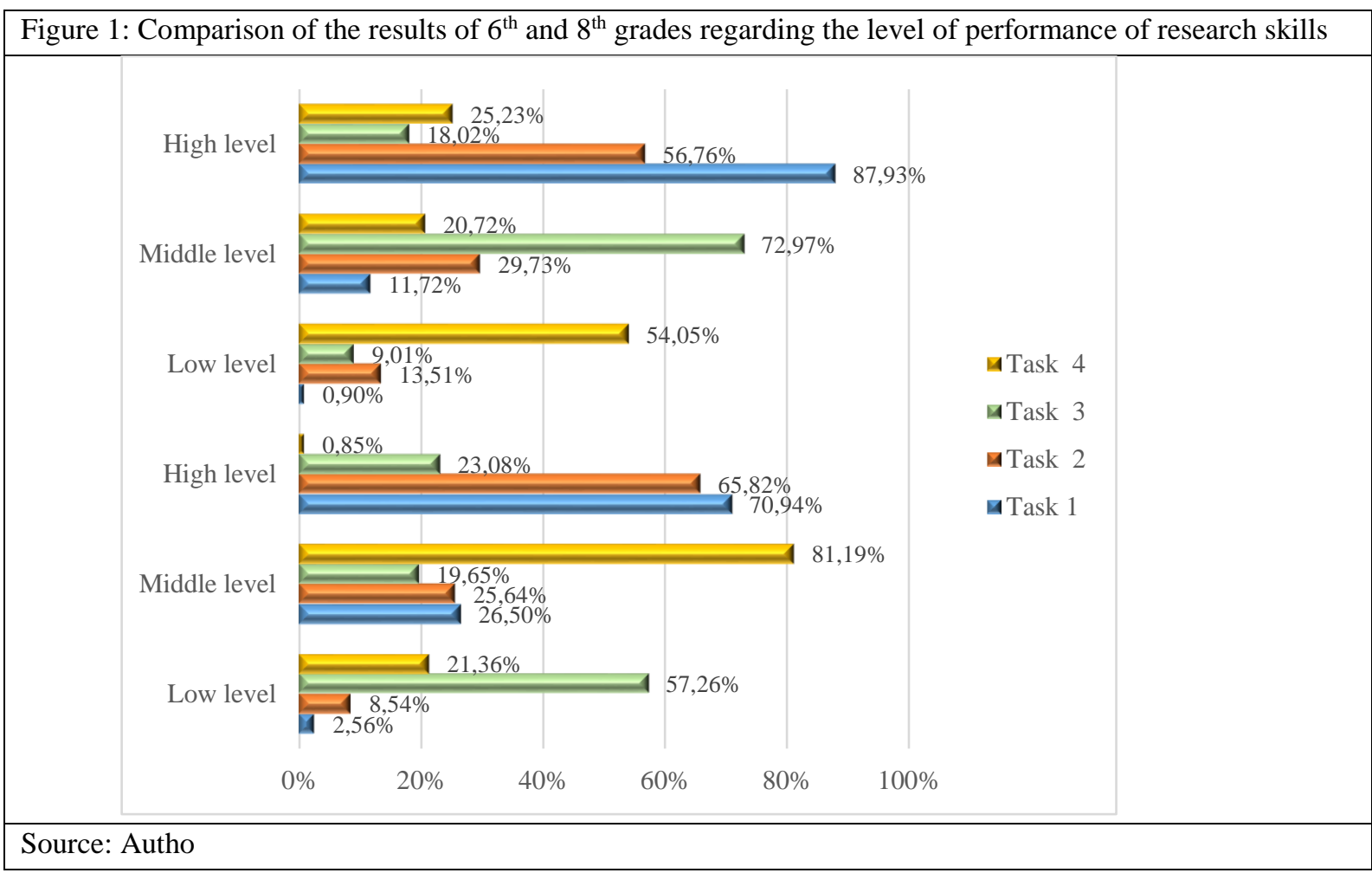

Detected bottlenecks in the transfer of competence in the third and fourth tasks occur progressively at the fifth and sixth task, too. The correct answers to task 5 are $12.50 \%$ less than the correct ones in regards with the correlation "knowledge, synthesis, application." The downward trend is clearly manifested in the sixth task in expression levels "synthesis and assessment," where only 26.79 percent of the students give correct answers. The incorrect answers dominate with $73.21 \%$ (Fig.2).

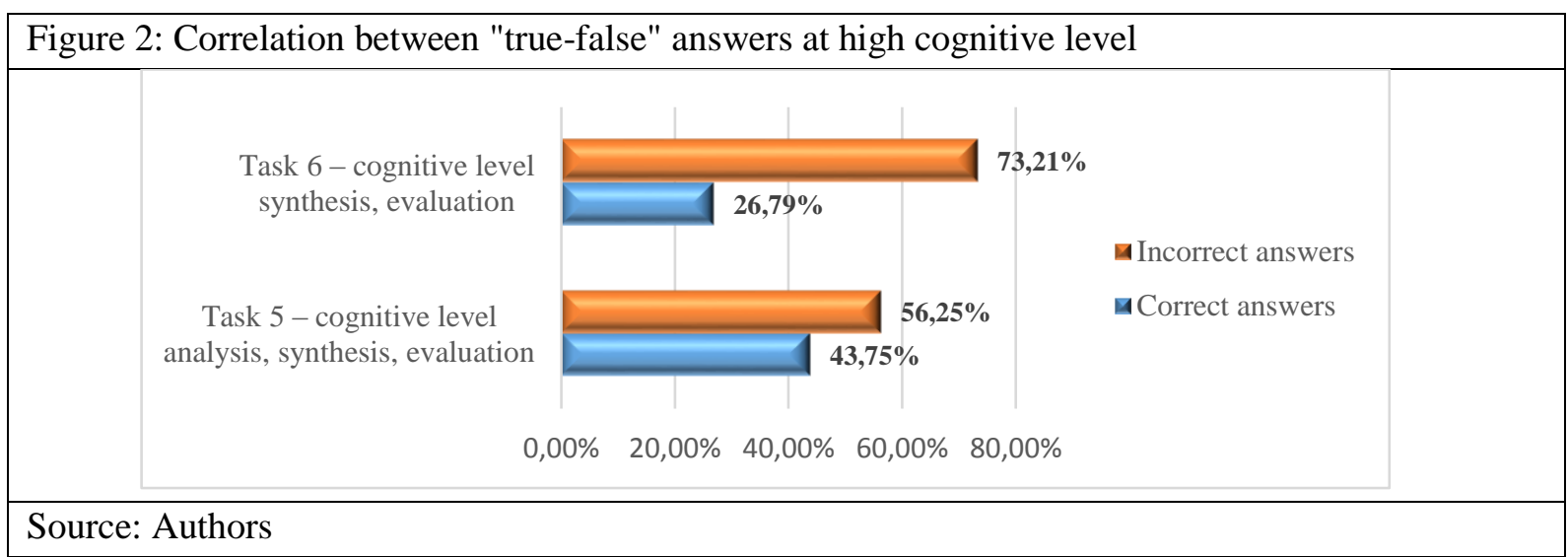

\section{Conclusion}

The conducted pedagogical study provides results that at this stage do not allow outlining the contours of an optimistic picture of the research skills in technology and entrepreneurship of students in the lower secondary level of the Bulgarian school. The main problem consists in continuing adherence of the teachers to methodical schemes adhering students to express reproductive thinking. 
The expected change in the standards of the educational environment, including the training in technologies and entrepreneurship will enable teachers to more easily switch to the application of modern method-based approaches of Edward de Bono (1994) to develop "lateral thinking" approaches, "learning by doing", "learning by experience", "project-based learning", and so on.

\section{References:}

Bono, D. (1994). Lateral Thinking: Creativity Step by Step. Penguin Group.

Dimitrov, N. (2013). Въведение в научните изследвания. Пловдив: Интелексперт-94.[Introduction to research. Plovdiv: Intelekspert-94]

Ministry of Education and Science of the Republic of Bulgaria. (2015, 11). Наредба №5 за общообразователната подготовка. 4. [Regulation №5 for general education] Retrieved from http://www.mon.bg/?:

http://www.mon.bg/?go=page\&pageId=1\&subpageId=25

Mitova, D. (2011). Проектно ориентирано технологично обучение: теория и методика [Project-based technological learning: theory and methodology]. Blagoevgrad: Neofit Rilski University Press.

Mitova, D. (2014). Developing Fundamental Skills at Students Using Technological Education. Developing Fundamental Skills at Students Using Technological International Journal Scientific and Applicative papers V-7, V-7, 221-225.

OECD. (2013). PISA 2012 Assessment and Analytical Framework: Mathematics, Reading, Science, Problem Solving and Finan $\neg$ cial Literacy. doi:http://dx.doi.org/10.1787/9789264190511-en.

Petrova, S. (n.d.). Assessing the competence to solve problems in PISA 2012. Retrieved from http://www.ckoko.bg/upload/docs/2014-04/PS_Chapter_BGR.pdf

Plachkov, S. (2013). Harmonizing the competency profile of the teacher in technology training with the European Qualifications Framework. Journal for information technology, education development and teaching methods of technical and natural sciences, 3, 1-5. 